\title{
Platypnea-Orthodeoxia Syndrome in patient with patent foramen ovale, dilated ascending aorta and persisting eustachian valve: A case report
}

\author{
Julie H Larsen*, Mikael K Poulsen, Kristian A Oevrehus and Michael Maiborg \\ Odense University hospital, Denmark
}

\begin{abstract}
Platypnea-Orthodeoxia Syndrome (POS) is a rare condition characterized by dyspnoea and hypoxia in upright position and symptom relief in supine position. The etiology is multifactorial depending on an interatrial defect and a functional component, which increases the right-toleft shunting in upright position. We report the case of a 68-years-old woman known with hypertension, dilated ascending aorta, two minor strokes and one episode of transient ischemic attack, admitted with severe dyspnoea and desaturation to $71 \%$ without oxygen supply. The patient experienced worsening of symptoms in vertical position and relief when lying down. Initially, pulmonary embolism was suspected, but refuted by computed tomography and ventilation/perfusion scintigraphy. The scintigraphy demonstrated tracer activity in multiple organs, which indicated a right-to-left shunt. Transesophageal echocardiogram (TEE) demonstrated a patent foramen ovale and a persisting eustachian valve resulting in right-to-left shunting, consistent with POS. Right heart catherization demonstrated normal pulmonary artery pressure of $12 \mathrm{mmHg}$ ruling out pulmonary hypertension before the patient underwent PFO occlusion and gained full recovery. When POS is suspected, postural provocation should be considered when performing TEE and right heart catherization to demonstrate worsening of right-to-left shunting in upright position. In the cardiology emergency departments, POS is a rare but important differential diagnosis to pulmonary embolism.
\end{abstract}

\section{Introduction}

Platypnoea-orthodeoxia syndrome (POS) is a rare and complex condition characterized by postural dyspnoea and deoxygenation with improvement of symptoms and blood oxygen saturation in supine position [1]. The descriptive term platypnea derived from Greek platus (flat) and pnoia (breath) describes the shortness of breath improving in flat position [2]. Orthodeoxia is the descriptive term for deoxygenation of arterial blood in upright position from Greek ortho (upright) and deoxia (less oxygen) [1]. It is theorized that both an anatomical and a functional component must exist to cause the syndrome [3]. The anatomical component being an interatrial defect through which a right-to-left shunt can occur. The most frequently interatrial defect is a patent foramen ovale (PFO) and less frequently an atrial septum defect (ASD) or a fenestrated interatrial aneurysm [3]. The hypothesis is that the functional component increases the right-to-left shunting in upright position due to deformation of the atrial septum and/or redirection of the bloodstream towards the interatrial defect [3]. The functional component may be either cardiac (chiari network, persisting eustacian valve, pericardial effusion), aortic (ascending aorta aneurism, aortic root elongation or aneurism), pulmonary (pneumonectomy, lobectomy, pulmonary emphysema), skeletal (kyphosis) or muscular (unilateral paralysis of the diaphragm) [1,4,5]. Although the interatrial defects mainly are present from birth, the functional component usually develops later in life, explaining the late onset of POS. Shortness of breath is a common symptom in emergency departments most commonly caused by pulmonary or cardiovascular disease [6]. We report a case of POS, where shortness of breath initially was thought to be cause by pulmonary embolism and we describe the comprehensive investigations the patient underwent before diagnosed with POS.

\section{Case presentation}

A 68-years-old woman (body surface area (BSA) $1.66 \mathrm{~m} 2$ and BMI $23.6 \mathrm{~kg} / \mathrm{m} 2$ ) with a medical history of hypothyroidism, treated hypertension, a mild dilation of the ascending aorta, prior history of two minor ischemic strokes and an episode of transient ischemic attack was admitted to the cardiological emergency department. The patient presented with shortness of breath worsening in upright position and during mobilization to upright position. The patient experienced symptom relief at rest in supine position. Onset of mild dyspnoea was about 1 month prior to admission and the patient experienced the dyspnoea worsening gradually over time when walking up the stairs. The last few days until admission the worsening escalated and the patient experienced dyspnoea when walking around in her house. Furthermore, a few days before admission, the patient experienced onset of dizziness, malaise, and mild chest pain worsening at lowintensity activity. At the cardiological emergency department, the patient presented with peripheral cyanosis, oxygen saturation of $71 \%$ and jugular vein distention. After lying down with oxygen supply

${ }^{\star}$ Correspondence to: Julie Hempel Larsen, Odense University hospital, J.B Winsløws Vej 4, 5000 Odense C, Denmark, , E-mail: julie.hempel.larsen@rsyd. $\mathrm{dk}$

Key words: platypnea-orthodeoxia syndrome, hypoxia, dyspnea, right-to-left shunt, aortic disease, case report

Received: February 08, 2021; Accepted: February 19, 2021; Published: February 26,2021 
(5L per minute), saturation was increased above $92 \%$. Mobilizing in the bed to upright position caused dyspnoea and desaturation below $80 \%$. Arterial blood pressure was $139 / 88 \mathrm{mmHg}$, heartrate 97 beats per minute and no cardiac murmur was heard. Initially, arterial blood sample without oxygen supply demonstrated oxygen saturation $76 \%$, partial pressure of oxygen 4.7, partial pressure of carbon dioxide 3 , and pH 7.54. Blood samples demonstrated normal D-dimer and normal high-sensitive cardiac troponin T. Electrocardiogram (ECG) showed sinus rhythm without signs of ischemia or right ventricular strain. A transthoracic echocardiogram (TTE) demonstrated normal dimensions of the left ventricle, normal ejection fraction, a mild dilation of the aortic root and a tricuspid aortic valve with a trivial insufficiency. It was noted that it was not possible to visualize the right ventricle and atrium. The patient had moderate risk of pulmonary embolism with Well's Score 3 point ( 3 points for pulmonary embolism being the most likely cause of symptoms). Because of severe desaturation, dyspnoea and moderate risk of pulmonary embolism, acute computed tomography (CT) angiogram of pulmonary arteries was performed. The patient was known with mild dilation of the ascending aortic, and though less likely than pulmonary embolism, aortic dissection was suspected, and CT of the aorta was performed. Central pulmonary embolism and aortic dissection was refuted. Furthermore, CT angiogram confirmed dilation of the ascending aorta measuring $44 \mathrm{~mm}$ with a relatively horizontal course with increased aortic root angulation of 70 degrees and the aortic root with close relation to the right atrium (Figure 1). Due to the persistent dyspnoea, peripheral pulmonary embolism was suspected. Ventilation/perfusion scintigraphy was performed without signs of pulmonary embolism, but tracer activity was observed in kidneys, spleen, stomach, and brain indicating a rightto-left shunt. A transoesophageal echocardiogram (TEE) in supine position demonstrated that the right atrium and superior vena cava being compressed by the dilated aorta. Combination of the dilated aorta compressing the right atrium and a prominent eustachian valve conducted blood flow from the inferior vena cava towards a patent foramen ovale (PFO) (Figure 2). This resulted in a significant right-toleft intracardiac shunt. To further quantify the intracardiac shunt and assess the etiology, a right heart catheterization was performed. This indicated an insignificant left-to-right shunt in supine position, shunt ratio 1.2 and normal pulmonary artery pressure of $12 \mathrm{mmHg}$ ruling out pulmonary hypertension (Table 1). The combination of postural dyspnea and desaturation, relief of symptoms in supine position and TEE demonstrating PFO with right-to-left shunt was consistent with

Table 1. Measurements from right heart catherization in supine position at rest

\begin{tabular}{|c|c|c|c|}
\hline \multicolumn{4}{|l|}{ Right heart catherization } \\
\hline Oxygen supply on high flow oxygen mask & \multicolumn{3}{|c|}{$65 \%$ oxygen, $35 \mathrm{~L}$ per minute } \\
\hline Peripheral saturation (percentage) & \multicolumn{3}{|c|}{98} \\
\hline Aorta saturation (percentage) & \multicolumn{3}{|c|}{98} \\
\hline Heart rate (beats / min) & \multicolumn{3}{|c|}{55} \\
\hline Cardiac output at rest (L/min) & \multicolumn{3}{|c|}{3.8} \\
\hline Cardiac output index at rest $(\mathrm{L} / \mathrm{min} / \mathrm{m} 2)$ & \multicolumn{3}{|c|}{2.3} \\
\hline Pulmonary vascular resistance & \multicolumn{3}{|c|}{1.3} \\
\hline \multirow[t]{2}{*}{ Shunt-ratio } & \multicolumn{3}{|c|}{1.2} \\
\hline & $\begin{array}{c}\text { Mean } \\
\text { pressure at } \\
\text { rest }(\mathrm{mmHg})\end{array}$ & $\begin{array}{c}\text { Max pressure } \\
\text { at rest } \\
(\mathrm{mmHg})\end{array}$ & $\begin{array}{l}\text { Saturation } \\
\text { (percentage) }\end{array}$ \\
\hline Superior vena cava & & & 70 \\
\hline Inferior vena cava & & & 76 \\
\hline Right atrium & 5 & & 75 \\
\hline Right ventricle & 4 & & 75 \\
\hline Pulmonary artery & 12 & 19 & 76 \\
\hline Pulmonary capillary pressure & 7 & & 95 \\
\hline
\end{tabular}
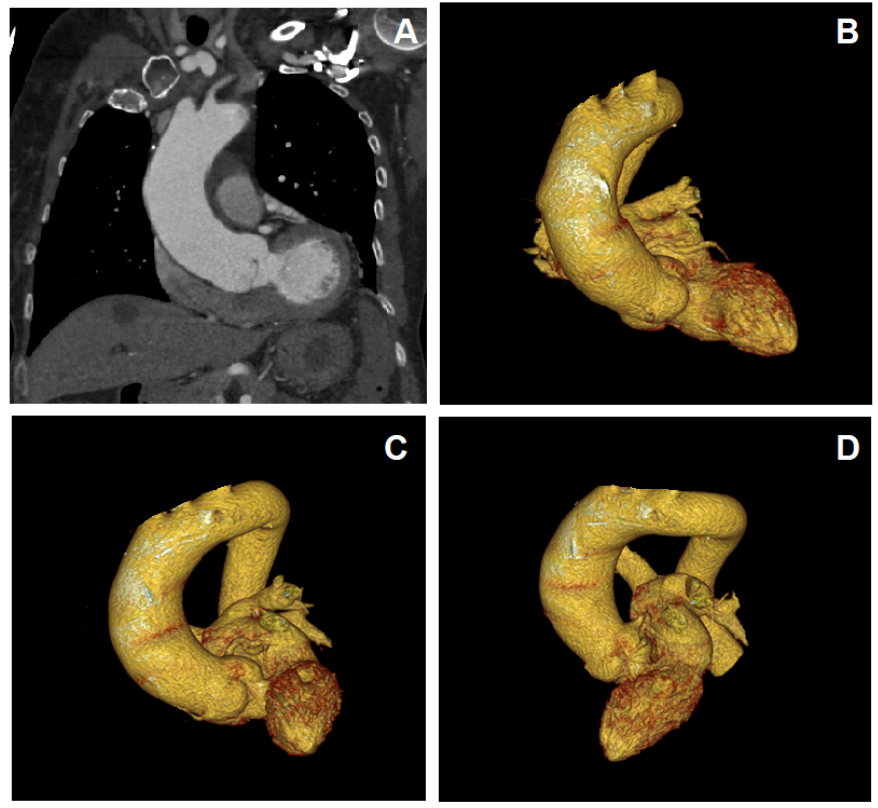

Figure 1. Computed tomography image showing the horizontal course of the ascending aorta towards the left ventricle. (A) anterior view (B), (C), (D) 3D images in anterior, apical and posterior view, respectively
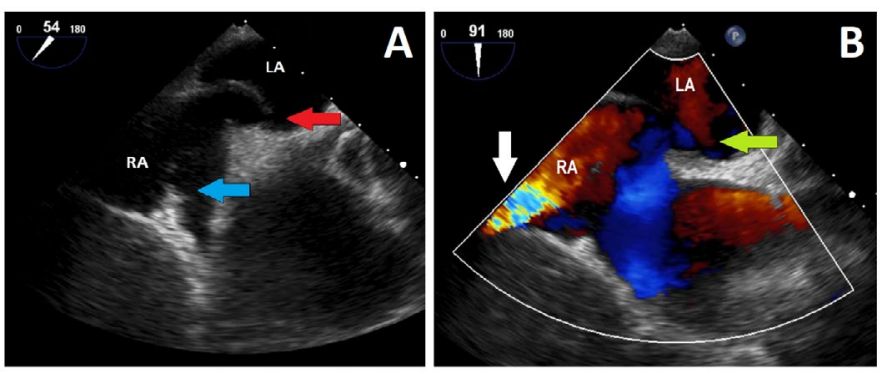

Figure 2. Transoesophageal echocardiogram. RA, right atrium; LA, left atrium. (A) showing the persisting eustachian valve (blue arrow) and patent forman ovale (red arrow). (B) Colour doppler showing accelerated blood flow from the inferior vena cava (white arrow) towards the patent ovale (green arrow)

POS. Furthermore, pulmonary hypertension was refuted before the patient was referred to percutaneous closure of the PFO. A Cocoon PFO Occluder was successfully implanted. A post procedure TTE was performed without signs of residual shunt. The patient had immediately symptom relief. At 4- and 17-month control, TTE showed a well-placed closure device and no residual shunt. Due to 3 weeks hospitalization, the patient continued experiencing exhaustion a few months after discharged from the hospital.

\section{Discussion}

In the case presented above, the patient went through a comprehensive examination, before she was diagnosed with POS. In the cardiology emergency department, a common cause for severe dyspnea and desaturation is pulmonary embolism. Therefore, pulmonary embolism was suspected in this patient due to the severe desaturation to $71 \%$. At admission, the patient did not mention the onset of mild dyspnea one month prior to the admission, this was discovered later in the investigation. In-depth questioning of symptoms at admission is crucial since pulmonary embolism often has an acute onset. Ventilation/perfusion scintigraphy demonstrated tracer activity in kidneys, spleen, stomach and brain which indicated a right-to-left 
shunt and led to investigation towards POS. The right heart chambers were difficult to assess by TTE, thus TEE was performed. In general, TEE is better at assessing the atrial and interatrial anatomy [7]. Therefore, TEE is a useful diagnostic tool in detecting PFO and POS. Right heart catherization was performed in supine position without any significant shunting, which indicate the shunt being minimal in flat position. A significantly right-to-left shunt in upright position would be expected. As reported in other studies examination with postural provocation by tilt-table-test or alternatively provocative test simulating upright position (e.g., the Valsalva maneuver) would have added diagnostic value when performing both TEE and right heart catherization $[7,8]$. In cases with severe pulmonary hypertension, PFO occlusion has been correlated with worsening of symptoms due to the increased right sided pressure $[7,8]$. Therefore, right heart catheterization is crucial in the diagnosing the etiology of POS, ruling out pulmonary hypertension before PFO occlusion [7]. The patient reported in this case had a successful percutaneous catheter-based closure of PFO and gained full recovery. The association between the development of a right-to-left shunt and enlarged aortic root or aortic aneurysm has been described previously [9]. One study demonstrated an association between aorta size, atrial septum deformation and motility, and increased risk of shunting in patients with PFO [10]. Only few cases of patients with POS due to coexisting PFO, persisting eustachian valve and aorta enlargement has been reported [7]. It is suspected that the coexisting of a persisting eustachian valve and a dilated aorta, both contributed to the increased right-to-left shunt in upright position.

\section{Conclusion}

POS is a rare differential diagnosis to pulmonary embolism. POS should be suspected in patients with severe dyspnea and deoxygenation with postural worsening, especially when pulmonary embolism is refuted. When POS is suspected, postural provocation should be considered when performing TEE and right heart catherization to demonstrate worsening of right-to-left shunting in upright position.

\section{Statement of consent}

The patient in this case report has read the article, seen all material, and has given written consent to publish it.

\section{References}

1. Cheng TO (1999) Platypnea-orthodeoxia syndrome: etiology, differential diagnosis, and management. Catheter Cardiovasc Interv 47: 64-66. [Crossref]

2. Khauli S, Rajasurya V, Mahmoud N (2020) Platypnea, in StatPearls. 2020, StatPearls Publishing Copyright, StatPearls Publishing LLC.: Treasure Island (FL).

3. Cheng TO (2002) Mechanisms of platypnea-orthodeoxia: what causes water to flow uphill? Circulation 105: e47. [Crossref]

4. Guérin P, Lambert V, Godart F, Legendre A, Petit J, et al. (2005) Transcatheter closure of patent foramen ovale in patients with platypnea-orthodeoxia: results of a multicentric French registry. Cardiovasc Intervent Radiol 28: 164-168. [Crossref]

5. Knapper JT, Schultz J, Das G, Sperling LS (2014) Cardiac platypnea-orthodeoxia syndrome: an often-unrecognized malady. Clin Cardiol 37: 645-649. [Crossref]

6. Hutchinson A, Pickering A, Williams P, Bland JM, Johnson MJ (2017) Breathlessness and presentation to the emergency department: a survey and clinical record review. BMC Pulm Med 17: 53. [Crossref]

7. Blanche C, Noble S, Roffi M, Testuz A, Müller H, et al. (2013) Platypnea-orthodeoxia syndrome in the elderly treated by percutaneous patent foramen ovale closure: a case series and literature review. Eur J Intern Med 24: 813-817. [Crossref]

8. Henkin S, Negrotto S, Pollak PM, Cullen MW, O'Cochlain F, et al. (2015) PlatypneaOrthodeoxia Syndrome: Diagnostic Challenge and the Importance of Heightened Clinical Suspicion. Tex Heart Inst J 42: 498-501. [Crossref]

9. Townsend Rda S, Costa ALM, Gib MC, Neto FLD (2014) Platypnea-orthodeoxia syndrome in patients presenting enlarged aortic root: case report and literature review. Rev Bras Ter Intensiva 26: 313-316. [Crossref]

10. Bertaux G, Eicher JC, Petit A, Dobsák P, Wolf JE (2007) Anotomic interaction between the aortic root and the atrial septum: a prospective echocardiographic study. J Am Soc Echocardiogr 20: 409-414. [Crossref]

Copyright: (C2021 Larsen JH. This is an open-access article distributed under the terms of the Creative Commons Attribution License, which permits unrestricted use, distribution, and reproduction in any medium, provided the original author and source are credited. 